\title{
Economic-Ecological Analysis of Sustainable Development in Romania
}

\author{
By Roxana Sarbu ${ }^{1}$, Antoneta Marcela Niculescu ${ }^{2}$, \\ Ovidiu Andrei Cristian Buzoianu ${ }^{3}$, Svetlana Platagea Gombos ${ }^{4}$
}

\begin{abstract}
The intense industrial exploitation of resources and the continuous degradation of the environment have determined an ecological crisis of care requires a sustainable strategy. The concept of sustainable development permanently determines or re-evaluates the connection between man and nature and is committed to solidarity between the generations as a single viable option for long lung growth. In the article, the theme of the long-term impact in the world terms on the processes developed in Romania is presented and analyzed, a necessary passage for a sustainable economic growth, but there is an existing resource and the possibility to stimulate and capitalize on an economic factor in this the transition to this new stage of use.
\end{abstract}

Keywords: sustainable development, strategies, ecological, perspectives

\section{Introduction}

The ecological crisis caused by the intense industrial exploitation of resources and the continuous degradation of the environment require a solution (Bran et al., 2018). It finds its shape in sustainable development and seeks first and foremost to preserve the quality of the environment (Burlacu et al., 2019). At present, the concept has expanded on the quality of life in its complexity, also in economic and social aspect (Ionita et al., 2009) (Angheluta et al., 2019).

The object of sustainable development is now also the concern for justice and equity between states, not only between generations (Bodislav et al., 2019). The concept of sustainable development determines a permanent reassessment of the links between man and nature and advocates solidarity between generations as the only viable option for long-term development (Rădulescu et al., 2018). Sustainability is based on the idea that human activities are dependent on the environment and resources (Băltărețu A., 2007).

Health, social security and economic stability of the society are essential in defining the quality of life (Carra, C. et al., 2018). Sustainable development of local communities in Romania is both a challenge and a priority at the same time. A challenge, because a community must be receptive to external and internal transformations and changes that can affect it, adapting to these changes through local strategic actions and initiatives (Androniceanu et al., 2017).

This paper deals with the main topics related to the sustainable development process in Romania. It presents basic notions regarding the sustainable development (Rogers P., 
2007).

The measures that are and are to be applied in Romania are set out in order to achieve an efficient sustainable development, in accordance with the framework provided by the European Union (Jianu et al., 2019). The challenges presented in the issue of sustainable development, aspects of economic sustainable development in the Romanian context, as well as the means of implementing, monitoring and reporting the results of sustainable development in Romania are analyzed.

\section{Methodology}

This article is an extended revocation of the literature regarding the economic and ecological dimension for developments in the Romanian countries. An important aspect in the analysis of sustainable development is a real identical problem of the environment and the economic environment in the care according to the population. According to the World Commission for Environment and Development (WCED), sustainable care can be defined as that care, afterwards, it must be satisfying the needs presented, without being able to generate a possible kind to allow access to one's own needs".

\section{Data Collection}

The acquisition of data necessary for the realization of this article was made following the research of the statistical data offered by INSSE for the years 2014-2018.

\section{Results}

Sustainable development of local communities is both a challenge and a priority at the same time. A challenge, because a community must be receptive to external and internal transformations and changes that can affect it, adapting to these changes through local strategic actions and initiatives. A priority, because the way the locality develops affects its present and future chances (Matei E., 2004).

The current policy of the European Union is focused on the sustainable development of society from all points of view. To this end, it provides the Member States with various financial instruments designed to solve their economic and social problems (Cooper, P. J., 2004)

The concept of sustainable development has the premise that human civilization is a subsystem of the sphere, dependent on the fluxes of matter and energy within it, on its stability and self-regulation capacity (Borowy I., 2014).

The public policies elaborated on this basis, such as the present National Strategy for Sustainable Development of Romania, aim to restore and maintain a long-term rational balance between economic development and the integrity of the natural environment in forms understood and accepted by society.

For Romania, as a member state of the European Union, sustainable development is not one of the possible options, but the only rational perspective of national becoming, resulting in the establishment of a new paradigm of development through the confluence 
of economic, social and environmental factors (Albu L, 2005).

In order to achieve a sustainable development of the Romanian economy, it is necessary to achieve a sustainable economic trade (fair trade), a sustainable agriculture, sustainable consumption and use of renewable energy and sustainable and sustainable tourism (Farazmand, A., 2016).

It starts from the premise that achieving accelerated development in the medium and long term in all the three essential components (economic, social and environmental) is not only one of the possible options, but represents the essential condition for the gradual reduction (Benaim, C.A., 2008), within a time horizon. as short as possible, of the gaps that still separate Romania from the average EU level in terms of quality of life and to ensure real cohesion, both nationally and within the wider European Union.

The economic evolution of Romania over the last 7 years (2012-2018), with an average annual growth rate of gross domestic product of over $8 \%$, compared to a rate of less than $4 \%$ in the EU-27, shows that achieving this objective is possible.

Entering the Single Market of the European Union, improving the business environment and the competitive environment, strengthening the private sector, increasing the rate and quality of investments are encouraging factors that favor the continuation of this process.

Table 1- Gross Domestic Product

\begin{tabular}{|l|c|c|c|c|c|}
\hline & $\mathbf{2 0 1 4}$ & $\mathbf{2 0 1 5}$ & $\mathbf{2 0 1 6}$ & $\mathbf{2 0 1 7}$ & $\mathbf{2 0 1 8}$ \\
\hline GDP & 101,3 & 103,0 & 105,0 & 105,0 & 106,0 \\
\hline Privat consume & 101,0 & 102,8 & 104,7 & 104,7 & 105,6 \\
\hline Gouvernamental consume & 101,7 & 100,1 & 100,6 & 100,4 & 101,1 \\
\hline Gross capital formation & 104,7 & 107,2 & 109,5 & 109,2 & 110,8 \\
\hline Exports of goods and services & 107,3 & 108,7 & 108,8 & 108,5 & 109,1 \\
\hline Imports of goods and services & 108,2 & 108,7 & 108,6 & 108,2 & 109,2 \\
\hline
\end{tabular}

Source: INSSE, 2019

Given the extension of the free movement of goods and services and the effects of globalization, competitiveness and eco-efficiency will be determining factors of the sustainability of the economic growth (Hickel J., 2019).

Ensuring the medium and long term performance of the Romanian economy therefore requires the adoption of efficient economic policy instruments, which will allow the substantially improved management and capitalization of the potential existing in certain key areas, which determines sustainable development in a competitive environment.

In terms of ensuring the long-term sustainability of energy and material consumption based on the realistic assessment of the support capacity of the natural capital, the primary and final energy intensity are, in Romania, more than three times higher than the current average levels in the EU. It follows that there is an important potential for reducing energy consumption, the main source being the increase of energy efficiency in the productive sectors of goods and services, and the reduction of considerable energy losses in the residential sector (James P., 2015).

In order to ensure the sustainability of the total consumption of material resources in relation to the responsible management of the natural capital, a significant improvement 
of the productivity of the resources is required as a priority concern (Wallace B., 2005). It is foreseen that the EU's primary and secondary legislation in this area will evolve towards setting more ambitious goals and more demanding regulations, in line with the renewed Lisbon Agenda.

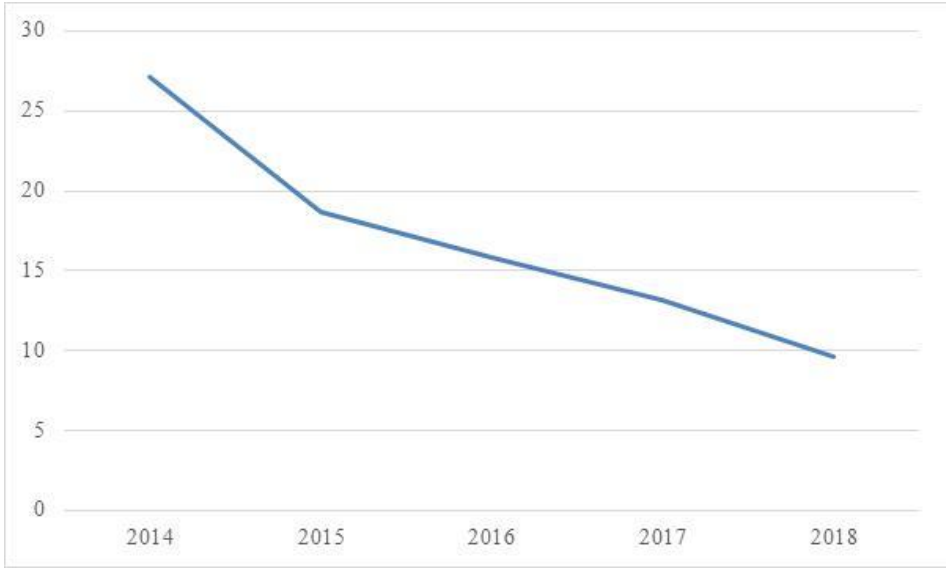

Figure 1- Growth of consume prices (variations, \%/year)

Source: INSSE, 2019

From the analysis of the evolution of the manufacturing industry in Romania in recent years, it has resulted, for example, in the energy- and material-intensive sectors (metallurgy, oil processing, substances and chemicals, building materials), which, in addition, are polluting and represents $25 \%$ of the total production, the tendency to reduce the productivity of the resources is due to the increase of the intermediate consumption. Compared to 2014, in 2018 the total consumption of resources in the metallurgical industry increased by over $48 \%$, while the added value decreased by $2.8 \%$. In the oil processing industry, at an increase of $12.6 \%$ of the added value, the consumption of resources increased by over $50 \%$.

In this case, it is noted that there is significant potential for substantial improvement of the situation, within a reasonable time, by promoting policies that stimulate technological modernization and increase the share of advanced processing products, both for export and for domestic consumption.

Given the significant increase in the share of imports of primary energy resources and raw materials in the future, it is necessary to develop a special strategy both for diversifying the sources of supply and for securing them through long-term agreements (Farah P.D., 2015).

In the analysis of the gradual modernization of the macro-structure of the economy to meet the social and environmental demands, it was observed that the share of services in GDP formation increased from $48.8 \%$ in 2006 to about 55\% in 2013 and $60-65 \%$ in 2020 and their quality it will also determine the increase of economic efficiency and competitiveness in the other economic sectors, with beneficial social effects on the vertical mobility of the workforce and the level of qualification and remuneration.

The most profound changes will take place in the rural area by largely replacing, during 
the life of a single generation, archaic structures, production practices in agriculture and the appearance of the Romanian village, under the conditions of preserving the specific local and cultural identity.

Development of organic agro-food production, training of local communities in ecological and conservation activities of the natural environment, their direct co-interest in protecting monuments and sites with historical value or cultural heritage, ensuring access to basic communal and social services, reducing and eliminating poverty, the improvement of communications and market relations will contribute to the gradual closing of the discrepancies regarding the quality of life between the village and the city.

\section{Discussion}

The slow renewal of the technological base, the inferior quality of the infrastructures, the chronic underfunding, the weak contribution of its own researchdevelopment-innovation activities, the poor performances of the products and services offered on the market, the insufficient capacity to adapt to the demands of the globalized market were the main causes that have negatively influenced both the productivity of labor and the efficiency of the use of resources. Although in recent years the growth rate of labor productivity in Romania, especially in the processing and construction industries, has been higher than the EU average, the difference remains very high.

As the productivity of material resources (efficiency of use) and labor productivity are the main determinants of efficiency and competitiveness and, implicitly, of the sustainability of economic and social development, considerable efforts are needed, investment and management, to remedy the situation and to align with the current standards of the European Union.

At the same time, it is necessary to improve the employment rate of potentially active workforce, which in 2012-2016 was $57.9 \%$ in Romania, compared to the EU average of $63.1 \%$ in the same period.

Through the policies to increase investments in human capital, an employment rate of the population between 15 and 64 years is estimated to be over 64-65\%, by 2020 .

In the following periods, a considerable increase of the quality of the economic management is required at all levels, from the national or regional level to the level of enterprise or agricultural exploitation, for the efficient and complete use of the available capital resources and to attract additional sources of financing for investments both in equipping with modern technology, as well as in training and improving the workforce, in scientific research, technological development and innovation.

As the sustainable growth of the gross domestic product is determined by the evolution of the added value achieved by the economic operators, the expansion of the performance management is crucial in all the main links of the activity of each unit producing goods or services: administrative and technical, technological, financial, logistic, commercial, as well and in human resource management.

The implementation in the current activity of the companies of the elaboration of multiannual budgets, at least in the medium term, is necessary both to ensure a long-term vision regarding the development perspective, as well as to base efficient policies in the field of investments and to adapt the volume and structure of the production of goods 
and services to the anticipated market trends.

Table 2- Balance of payments components

\begin{tabular}{|l|c|c|c|c|c|}
\hline & $\mathbf{2 0 1 4}$ & $\mathbf{2 0 1 5}$ & $\mathbf{2 0 1 6}$ & $\mathbf{2 0 1 7}$ & $\mathbf{2 0 1 8}$ \\
\hline Exports of sizes and services (billion \$) & 10,9 & 11.2 & 11,9 & 12,5 & 13,8 \\
\hline Imports of goods and services (billion \$) & 12,4 & 12,9 & 13,6 & 14,5 & 15,9 \\
\hline Current account deficit (billion \$) & $-1,7$ & $-1,9$ & $-2,1$ & $-1,8$ & $-2,2$ \\
\hline Net foreign direct investments flow (billion \$) & 1,8 & 2.1 & 2.3 & 1,9 & 2.0 \\
\hline External debt (\% of GDP) & 31,3 & 31,7 & 29,8 & 30,1 & 28,6 \\
\hline Total external debt (billion \$) & 10,7 & 11,2 & 11,8 & 12,5 & 13,3 \\
\hline Gross foreign exchange reserve (billion \$) & 3,9 & 4,2 & 5,3 & 5,9 & 6,6 \\
\hline
\end{tabular}

Source: INNSE, 2019

Romania's specific development needs and ensuring the compatibility of economic, social and environmental policies with the main evolution line within the EU requires the active and responsible involvement of central and local public institutions, the private sector, professional associations, social partners and civil society in maintaining a favorable business environment for domestic and foreign

capital investments aimed at modernizing and sustainable development of the country.

The development of saving instruments, based on the practices successfully applied in other EU countries, may include: developing a market on which government bonds, public and corporate bonds, long-term placement instruments to be freely traded and natural persons; regulating a mortgage market in which both rights and, especially, mortgage guarantees can be freely traded; stimulation of collective investment instruments and institutions, respectively of additional pension and life insurance funds, which can attract significant amounts through long-term commitments (15-20 years); encouraging savings banks to expand their activities in rural areas. It is also useful to examine the costs and benefits of using tax instruments to stimulate savings.

The development of public-private partnerships should not be limited to concessions, although they should be further encouraged, under favorable economic-financial conditions for sustainable development. Establishing new companies, partially capitalized by initial public offers (IPO), in which the state or local authority holds a minority stake in the company that makes the investment and operates it, but which is subsequently capitalized by listing on the stock exchange, may be another solution for reducing the initial budgetary effort and maintenance costs after the commissioning of infrastructure investments. Reducing the participation of public money diminishes at the same time the potential for corruption and the negative effects on the efficiency of investments.

Achieving a sustainable economic growth, defined by the average annual rates of GDP evolution, and the operational targets of the present Strategy by the year 2030, is conditioned by the implementation of an adequate and coherent set of economic policies that are in line with the objectives agreed within the EU, in particular with the revised Lisbon Strategy.

The monetary policy and the exchange rate will follow the continuation of the downward trajectory of inflation, starting with the second part of 2020. The targets for the following years are $3.8-5 \%$ and $3.5-4.5 \%$, respectively to be within the convergence limit 
and to remain close to this level in the next period. The aim is to ensure a higher degree of stability of the medium-term exchange rate and of the anticipations regarding its evolution as a result of being within the limits of the convergence criteria.

As regards supporting the sustainable development of cities as urban growth poles, actions will focus on increasing the quality of life and creating new jobs by rehabilitating urban infrastructure, improving urban services, including social services, and developing support structures.

\section{Conclusions}

The economic pillar of Romania's sustainable development, to which the social, environmental and cultural complementary and independent are added, has several objectives and priorities.

A fundamental macroeconomic objective is the permanent growth of the GDP, based on the application of the contemporary strategic and technical program, at relatively high rates, which will ensure the achievement of the average level of GDP per capita of the EU-27 in a realistic time horizon.

This increase implies a sustained investment effort, with high efficiency, a high dynamics of the total productivity of the production factors, but above all meeting the criterion of the eco-efficiency to "achieve more and less" consumption of natural and human resources.

The most dynamic sectors were: trade, construction, transport and communications, the processing industry, especially on the basis of natural resources (wood and wood products processing; cellulose; paper and paper products; rubber and plastic products, materials of constructions, metal constructions and metal products, etc.).

Trends in final energy consumption in EU countries show significant improvements in the industrial and service sectors. In the case of Romania, on the contrary, there is an extensive increase of this type of consumption in industry and transport. Judging in terms of reducing greenhouse gas (GHG) emissions, the data indicate a favorable trend for change. For eco-efficiency, it is necessary to promote market instruments that reflect the true costs of using natural resources and the impact on society (environmental taxes, flexible emission trading schemes, subsidies, etc.).

The high elasticity of the parameters of poverty at economic growth is an important premise of the policy to combat poverty, in the conditions of maintaining the tendency of economic growth in the last years. Poverty alleviation imposes policies to support income in the poor area of distribution on social transfers in favor of families with children, the population outside the labor market and the unemployed, as well as on raising the minimum wage. Also, the promotion of policies for the development of human capital and employment, meant to support the ability to make higher and safer incomes, is part of the rationale for the progress for sustainable development.

\section{Acknowledgements} productions.

I would like to thank INSSE for their help to data collection on crop 


\section{References}

Albu L., Dobrescu E., 2005. Dez̧oltarea durabila in Romania, Editura Expert, București

Allen, C., \& Clouth, S., 2012. Green economy, green growth, and low-carbon development - history, definitions and a guide to recent publications. UNDESA: A guidebook to the Green Economy.

Androniceanu, A., Burlacu, S., Drăgulănescu, I. V., \& Nicolae, E. E. (2017, May). New trends of businesses digitalization in Romania and the behaviour young consumers. In BASIQ International Conference: New Trends in Sustainable Business and Consumption, Graz (Vol. 31, pp. 27-35).

Angheluta, S. P., Burlacu, S., Diaconu, A., \& Curea, C. S. (2019). The Energy from Renewable Sources in the European Union: Achieving the Goals. European Journal of Sustainable Development, 8(5), 57.

Băltărețu A., 2007. Ecoturism şi dęvoltare durabilă, Editura Prouniversitaria, Bucureşti

Benaim, C.A., \& Raftis, L., 2008. The Social Dimension of Sustainable Development: Guidance and Application: Thesis submitted for completion of Master of Strategic Leadership towards Sustainability, Blekinge Institute of Technology, Karlskrona, Sweden

Bodislav, A. D., Rădulescu, C. V., Moise, D., \& Burlacu, S. (2019). Environmental Policy in the Romanian Public Sector. The Bucharest University of Economic Studies Publishing House, 312.

Borowy I., 2014. Defining Sustainable Development for Our Common Future. A bistory of the World Commission on Environment and Development (Brundtland Commission), Milton Park: Routledge

Bran, F.., Alpopi, C., \& Burlacu, S. (2018). Territorial Development-Disparities between the Developed and the least Developed Areas of Romania. LUMEN Proceedings, 6(1), 146-155.

Breuer, A., Janetschek, H., \& Malerba, D., 2019. Translating sustainable development goal (SDG)Interdependencies into policy advice: Sustainability. Bonn,b Germany: MDPI German Development Institute (DIE)

Burlacu, S., Alpopi, C., Mitrită, M., \& Popescu, M. L. (2019). Sustainable e-Governance and Human Resource Development. European Journal of Sustainable Development, 8(5), 16.

Carra, C., Burlacu, S., \& Faggianelli, D. (2018). Violence within the organizations of health and medico-social sector. A comparative analysis of France and Romania. Economics, Management and Financial Markets, 13(3), 185-202.

Carra, Cécile; Burlacu, Sorin; Faggianelli, Daniel. Violence in health organizations in Romania. The 13th Administration and Public Management International Conference. Policy And Organizational Change In Public Institutions, Oct 2017, București, Romania. 〈hal-01698150〉

Cooper, P. J., \& Vargas, M., 2004. Implementing sustainable development: From global policy to local action. Lanham, MD: Rowman and Littlefield Publishers, Inc.

Farah P.D., Piercarloc R., 2015. Energy: Policy, Legal and Social-Economic Issues Under the Dimensions of Sustainability and Security, World Scientific Reference on Globalisation in Eurasia and the Pacific Rim, SSRN 2695701

Farazmand, A., 2016. Global encyclopedia of public administration, public policy, and governance. Amsterdam: Springer International Publishing. doi:10.1007/978-3-319-31816-5_2760-1.

Hickel J., 2019. The contradiction of the sustainable development goals: Growth versus ecology on a finite planet. Sustainable Development, 27 (5): 873-884. doi:10.1002/sd.1947

Ioniță, F.; Burlacu, S. \& Gaidargi, A.(2009) MODERN APPROACHES OF THE MANAGEMENT OF ALTERNATIVE TRADE SYSTEMS, Revista de Management Comparat Internațional/Review of International Comparative Management,51, 473-480

James P., 2015, Urban Sustainability in Theory and Practice: Circles of Sustainability, London: Routledge

Jianu, I., Dobre, I., Bodislav, D. A., Radulescu, C. V., \& Burlacu, S. (2019). The implications of institutional specificities on the income inequalities drivers in European Union. Economic Computation and Economic Cybernetics Studies and Research, 53(2), 59-76.

Matei E., 2004. Ecoturism, Editura Top Form, Bucureşti

Nistoreanu P., 2003. Ecoturism şi turism rural, Editura A.S.E., Bucureşti

Rădulescu, C. V., Dobrea, R. C., \& Burlacu, S. (2018) The business management of distress situations. The 12th international management conference "Management Perspectives in the Digital Era" November 1st-2nd, 2018, Bucharest, Romania, 1, 741-747

Rogers P., Jalal K.F., Boyd J.A., 2007. An Introduction to Sustainable Development, Routledge, ISBN 1844075214

Wallace B., 2005. Becoming part of the solution: the engineer's guide to sustainable development, Washington, DC: American Council of Engineering Companies. ISBN 978-0-910090-37-7 